\title{
Methods for the study of accent bias and access to elite professions
}

\author{
Devyani Sharma ${ }^{1}$, Erez Levon ${ }^{1}$, Dominic Watt ${ }^{2}$, Yang Ye $^{1}$, Amanda Cardoso $^{3}$ \\ ${ }^{1}$ Queen Mary University of London, ${ }^{2}$ University of York, ${ }^{3}$ University of British Columbia
}

\begin{abstract}
Fair access to employment is vital for improving social mobility in Britain today. As language is not explicitly protected by the Equality Act 2010, accent can become a proxy for other forms of discrimination at key junctures for social mobility such as recruiting to elite professions. The Accent Bias and Fair Access in Britain project (www.accentbiasbritain.org) aims to assess prevailing attitudes to accents in Britain and to assess the extent to which accent-based prejudice affects elite professions. In this article we focus specifically on methodological innovations in this project, rather than detailed results. We describe our approach to four challenges in the study of accent bias: how to assess whether accent preferences actively interfere with the perception of expertise in candidates' utterances; how to more precisely identify sources of bias in individuals; new technologies for real-time rating to establish whether specific 'shibboleths' trigger shifts in evaluation; and how to assess the efficacy of interventions for combating implicit bias. We suggest integrating best practices from the fields of linguistics, social psychology, and management studies to develop sound interdisciplinary methods for the study of language, discrimination, and social mobility.
\end{abstract}

Keywords: Accent discrimination, legal profession, research methods, anti-bias interventions

\section{Introduction}

Upward social mobility has been remarkably stagnant in the United Kingdom since 1970 (Blanden, Goodman, Gregg and Machin 2005; Reay 2009; Smith 2010; Buscha and Sturgis 2017). Fair access to employment is vital for social mobility, and unequal outcomes for certain minority groups in professional hiring have been widely reported in the UK (e.g. The Guardian 12/6/14; Rich 2014; Zschirnt and Ruedin 2016). Successive Prime Ministers have pledged to tackle the issue (The Sunday Times 30/1/16; The Guardian 12/07/16).

Policing of language may play a part in selective access to socioeconomic success and social mobility. A survey by the Chartered Institute of Personnel and Development found that over $76 \%$ of employers admitted to discriminating against applicants on the basis of their accents, and only $3 \%$ of employers nationally include accent or dialect differences as a protected category (CIPD 2006). Relatedly, a recent study commissioned by the Social Mobility Commission determined that working class candidates are often unable to gain access to elite employment (e.g. law, medicine, financial services) despite having the relevant qualifications and skills because of informal 'poshness tests', including a candidate's style of speaking (Ashley, Duberley, Sommerlad, and Scholarios 2015).

Given this, it would scarcely be surprising if, for those seeking positions in elite professions, an ability to speak with a standard or close-to-standard accent of English (especially Standard Southern British English, SSBE, or 'Received Pronunciation') would be seen as advantageous. Yet most studies of bias in recruitment in the UK have not focused on the specific role of accent, and studies of accent bias have tended not to be based in the workplace. There remains a critical need to build on the few studies that have done this, and 
to develop a better understanding of the role of accent-based bias at key junctures of social mobility.

\section{The study of accent discrimination}

Most research into bias in hiring in the UK has focused on general social factors such as ethnicity and schooling, not accent. Heath and Cheung (2006) found worse outcomes for ethnic minority groups in terms of employment, rate of pay, and level of work attained, even while keeping education profile and age constant. In a field experiment, Wood, Hales, Purdon, Sejersen and Hayllar (2009) submitted matched job applications and confirmed a significant ethnic bias, with greater evidence of bias in private rather than public sector employment. Rates of admission to elite universities also differ by ethnicity despite identical school leaving results (The Telegraph 26/2/13).

It is well-known that accent encodes many of these social differences, particularly in the UK. For centuries, accent and dialect have played a central role in structuring British society and determining socioeconomic prospects (e.g., Puttenham 1589; Swift 1712; Shaw 1916; Fox 2004; Fry 2011; Jones 2011; Toynbee 2011). This constitutive role of accent in signalling class and education in the UK has fostered dangerously inaccurate public discourse about the language of minority groups (e.g. David Starkey equating "Jamaican patois" with "violent, destructive, nihilistic gangster culture", BBC Newsnight 12/08/11). The actualities of natural language variation and change can be obscured by social and political ideology, which can in turn lead to unconsciously discriminatory behaviour. Accent may thus be a key contributor to these patterns of bias, playing a part in perpetuating unequal access in Britain.

In the present article, we focus on four key methodological questions in this area, offering a critical evaluation of current practice and suggesting potential advances. These are:

a. How do we know whether a listener's accent preferences are actively interfering with their perception of expert content in a job candidate's utterance?

b. How do we establish the source of bias in listeners, when we identify such bias?

c. How do we know whether people are responding to the overall accent they are hearing, or to specific 'shibboleths'?

d. How effective are interventions in combating bias?

In this section, we first review existing research in these areas, noting important contributions and remaining gaps in previous work. In the section that follows, we turn to new research designs for each of these questions. All of the methodologies described here have been implemented; although the full set of results cannot be presented here, we briefly indicate preliminary findings for each method, along with wider implications.

\subsection{The study of accent preferences}

The field of sociolinguistics has examined the subjective perception of a range of British accents (e.g. Giles 1970, 1971; Trudgill 1974, 1975, 1986; Milroy and Milroy 1985; Kerswill 2001; Mugglestone 1995; Coupland and Bishop 2007; Montgomery 2007; Snell 2010). Garrett, Coupland and Williams (1999), Bishop, Coupland and Garrett (2005), and Coupland and Bishop (2007) identify systematic preferences for certain accents. Standard accents and accents associated with higher socioeconomic status, in particular RP, are perceived as being more prestigious and educated, although are often rated less positively for traits like friendliness. Conversely, non-standard accents - often urban, working class accents, though also some rural, regionally distinctive accents - are rated positively with regard to likeability and friendliness but are not perceived to signal educatedness and other prestige indicators. 
Most past surveys have relied on dialect labels rather than having listeners respond to actual audio stimuli. Studies that have examined real speech have tended to look at attitudes to individual varieties (e.g. Received Pronunciation; Fabricius 2005) or isolated linguistic features (e.g., Llamas, Watt and Johnson 2009; Clark and Schleef 2010; Levon and Buchstaller 2015; Llamas and Watt 2015).

Some early matched-guise studies examined attitudes to accents within professional contexts in Britain. Giles, Baker and Fielding (1975), for example, found that even when all other aspects of communication are kept 'standard' (grammar, lexis, speaking style), a speaker with a Birmingham accent was judged to be less intelligent and less appropriate for a job as a university lecturer than an RP speaker (see also Dixon, Mahoney and Cocks 2002). Similarly, Kalin, Rayko and Love (1980) found that English English was preferred in employment interviews over (standard) West Indian English, while Giles, Wilson and Conway (1981) reported that the lowest status jobs were seen as most suitable for speakers with non-standard accents (see Alemoru 2015 for a more recent study of these effects in relation to Multicultural London English). Qualitative studies have noted discrimination against non-native accents in the workplace even when comprehension or communicative effectiveness was not in question (Roberts, Davies and Jupp 1992), and self-suppression of regional accents for employment purposes (Baratta 2015). Many of these studies were conducted more than a decade or two ago, and there have been few systematic and comparative examinations of attitudes to different accents as they are actually spoken in contemporary Britain (Hiraga 2005 is one exception). There is therefore a need for an updated picture of current attitudes to real recordings of major British accents, as well as their role in professional outcomes.

The equivalent research literature on attitudes to accents in professional contexts outside the United Kingdom, particularly in the United States, is much larger and spans the fields of management studies, linguistics, and psychology. This research has shown that accent bias can lead to unequal outcomes in employment (e.g. Purkiss, Perrewé, Gillespie, Mayes and Ferris 2006), housing (e.g., Purnell, Idsardi and Baugh 1999; Baugh 2003; Du Bois this issue), and primary education performance (e.g., Rickford and Rickford 1995; Zentella 1997). These studies have explored a range of speech communities, including African American Vernacular English (e.g. Atkins 1993), Latino and Asian (e.g. Kushins 2014), regional German (Rakić, Steffens and Mummendey 2011), and non-native speech(e.g. Huang 2013).

Many of these studies focus only on accent effects, e.g. average differences in ratings on such scales as 'competence' or 'hireability'. This tends to leave unaddressed the question of whether or not these perceptions interfere with the ability to notice expertise when present. A number of studies, particularly in economics and management studies, have done this by adopting a research design targeted at tracking contextual or conditional effects in accent bias. In one of the best-known studies in this area, Bertrand and Mullainathan (2004) sent out identical resumés with White-sounding (e.g. Emily, Greg) and African-American-sounding names (e.g. Lakisha, Jamal), and found that resumés with white-sounding names received $50 \%$ more callbacks than those with black-sounding names. They also manipulated the quality of resumés and found that this had a significant impact on callbacks for resumés with White-sounding names, but not for those with African-American-sounding names (see also Carlson and McHenry 2006). Wang, Arndt, Singh and Biernat (2009) similarly found that in mock customer service encounters, American raters judged the service provided to be of lower quality when the service provider spoke with an Indian (vs. American or British) accent, but this bias was exacerbated when the requested service was unavailable (an effect also found in Tombs and Rao Hill 2013) and was reduced when more explicit information about the unavailability of the service was provided. This focus on not simply documenting 
preferences, but testing whether they affect the ability to judge competence, inspires the design of our experiment with law firms described later.

\subsection{Sources of bias}

In Psychology, bias, or systematic deviations in perception or judgement, has been established as a fundamental property of human cognition, argued to arise from information-processing pressures as well as from more emotionally-driven motivations (Tversky and Kahneman 1974; Bless, Fielder, and Strack 2004). Belief formation and human behavior has been shown to be extensively influenced by a wide range of such biases. A number of further factors may mediate the strength of such biases and whether they are traceable in people's self-awareness and self-reports. Examples of such moderating factors that are relevant to the present project include tolerance of diversity (Fuertes, Miville, Mohr, Sedlacek and Gretchen 2000), motivation to control prejudice (Dunton and Fazio 1997), and beliefs about the wider presence of prejudice in a given society (Swim, Aikin, Hall and Hunter 1995). We explore possible psychological bases for bias as well as factors that may mitigate their presence.

In the field of Economics, patterns of bias in hiring have been described in different terms. For instance, taste-based discrimination is described as deriving from personal social biases that may run counter to the goals of the corporation, while statistical discrimination derives from employers' risk-aversion and reliance on statistical observation in the face of imperfect information, leading to the potential for a vicious circle of marginalisation of atypical candidates (e.g., Becker 1957; Phelps 1972; Arrow 1973; Darity and Mason 1998). As part of either of these type of effects, British employers may use accent as a 'signal' (Connelly, Certo, Ireland and Reutzel 2011) of desirable or undesirable biographical attributes and thus as a tool for filtering out otherwise qualified candidates.

Although it can be very difficult to distinguish among such theoretical proposals, a sufficiently rich set of respondent data can begin to explore such hypotheses.

\subsection{The target of evaluative judgement}

We typically speak of subjective preferences for one accent over another, but of course speakers of a given accent have access to a range of phonetic and prosodic features, and interas well as intraspeaker variability in terms of density of accent features has been widely reported (Renn and Terry 2009; van Hofwegen and Wolfram 2010; Sharma and Rampton 2015). We know little about how accent density relates to attitudes, and the extent to which any such correlation is a consistent or accent-specific effect.

In recent work, attitudes towards specific linguistic features, rather than whole accents, have been shown to influence judgements (Campbell-Kibler 2008; Labov, Ash, Ravindranath, Weldon, Baranowski and Nagy 2011; Levon and Buchstaller 2015). For example, TH-fronting, where $/ \theta /$ is realised as [f], is perceived as being less professional by listeners in Northern England (Levon and Fox 2014). Attitudes toward an individual with a particular accent may therefore depend on the fine details of how they speak. Indeed, what we observe as accent bias may in some cases be an accentedness bias, e.g. not simply having a Multicultural London English (MLE) accent but having a strong MLE accent.

Until recently, very little research had investigated the effect of intraspeaker accent variation on attitudes. Recent work has begun to develop new technology for more precise real-time tracking of linguistic detail in subjective evaluation (Watson and Clark 2013; Montgomery and Moore 2018). We follow this work in designing ways to track the linguistic detail and target of subjective reactions.

\subsection{Anti-bias interventions}


It is very rare within the field of Linguistics to examine interventions of any sort. In other fields that deal more centrally with implicit bias, a range of interventions for decreasing biased judgement and decreasing reliance on heuristics have been developed and tested. Examples of such interventions include: increasing awareness of bias and commitment to objectivity (e.g. Axt, Casola and Nosek 2018), increasing accountability (e.g. Lerner and Tetlock 1999), committing upfront to selection criteria (e.g. Uhlmann and Cohen 2005), and various forms of stereotype-replacement and individuation (e.g. Devine, Forscher, Austin and Cox 2012). Some of these interventions aim to displace stereotypical associations while others aim to attenuate the impact of such associations on behaviour. In our research design we support engaging with this literature by testing a number of explicit and implicit types of intervention alongside a control condition that lacks an intervention. This permits a clearer understanding of the relative effectiveness of practical exercises for controlling accent bias in professional contexts. We include interventions that might resemble the preferred format in generic corporate diversity training along with other intervention designs based on previous findings.

\section{New methods for the study of accent bias}

The Accent Bias and Fair Access in Britain project (UK Economic and Social Research Council, www.accentbiasbritain.org) aims to assess many dimensions of attitudes to British accents, including the extent to which accent-based prejudice among gatekeepers of elite professions affects the career prospects of qualified applicants. Part of the project focuses on the legal profession, an environment in which traits like articulateness, authoritativeness, selfconfidence, and persuasiveness are highly prized. These traits have in the past been ascribed to the standard British English accent, Received Pronunciation (RP). This ascription is not just a tacitly agreed aspect of life in Britain: it is the subject of overt and usually approving discussion in many public fora, and it forms the foundation of best-selling self-help guides on speech and voice designed for businesspeople, actors, educators, and other public speakers (e.g. Sharpe and Rowles 2011; Ashton and Shepherd 2012; James and Smith 2012).

The wider project examines questions relating to accent bias (to what extent does a candidate's accent interfere with the assessment of their knowledge and professional competence?), regional and social differences (are patterns of bias similar across region, age, class, gender, and ethnicity in the UK?), the basis of bias (what individual or social characteristics does accent bias correlate with?), and interventions (can explicit and/or implicit interventions mitigate the effects of bias?).

The project brings together theories and methods from sociolinguistics, social psychology, and labour market economics. Sociolinguistics provides us with a detailed understanding of existing patterns of accent variation across regions and social groups in the UK. Social psychology provides us with experimental methods for testing listener attitudes to such variation. Finally, theories of discrimination in labour market economics and management provide us with a framework for conceptualising and pinpointing bias as well as for assessing interventions.

\subsection{Description of the experimental design}

The project focused on the judgement of five UK accents: Received Pronunciation (RP; e.g., Fabricius 2002), Estuary English (EE; e.g., Altendorf 2003), Multicultural London English (MLE; e.g., Cheshire, Fox, Kerswill and Torgersen 2008, 2011), Urban West Yorkshire English (UWYE; Beal 2004), and General Northern English (GNE; Watt 2002; Beal 2009). These accents are chosen because together they allow us to examine listener evaluations 
across a number of fundamental social contrasts, including region, prestige, localness, age of the variety, and ethnic and class associations. Table 1 summarises these dimensions of contrast.

Table 1: Social contrasts reflected by the five British English accents used for the stimuli

\begin{tabular}{|c|c|c|c|c|c|}
\hline \multirow[b]{2}{*}{$\begin{array}{l}\text { Social } \\
\text { Association }\end{array}$} & \multicolumn{5}{|c|}{ Accent } \\
\hline & RP & $\mathbf{E E}$ & MLE & GNE & UWYE \\
\hline Region & South & South & South & North & North \\
\hline Prestige & Standard & $\begin{array}{c}\text { Non- } \\
\text { standard }\end{array}$ & $\begin{array}{l}\text { Non- } \\
\text { standard }\end{array}$ & Standard & $\begin{array}{l}\text { Non- } \\
\text { standard }\end{array}$ \\
\hline Localness & National & Supra-local & Local & Supra-local & Local \\
\hline Age of variety & Established & $\begin{array}{l}\text { Newly } \\
\text { emergent }\end{array}$ & $\begin{array}{l}\text { Newly } \\
\text { emergent }\end{array}$ & $\begin{array}{l}\text { Newly } \\
\text { emergent }\end{array}$ & Established \\
\hline Ethnicity & White & White & Non-white & White & White \\
\hline Class & Middle class & $\begin{array}{c}\text { Working } \\
\text { class }\end{array}$ & $\begin{array}{c}\text { Working } \\
\text { class }\end{array}$ & $\begin{array}{l}\text { Middle } \\
\text { class }\end{array}$ & $\begin{array}{l}\text { Working } \\
\text { class }\end{array}$ \\
\hline
\end{tabular}

The five accents differ across a range of features, including the presence and prevalence of $/ \mathrm{t} / \mathrm{-}$ glottaling, ING fronting, /h/-dropping, TH-fronting, TH-stopping, and /1/-vocalisation; the realisation of liquids; the realisation of the STRUT, BATH, FOOT, and GOOSE vowels, as well as that of the MOUTH, FACE, GOAT, and PRICE vowels, to name just a few.

We opt for an experimental approach, derived from social psychology, rather than a field-based approach (e.g. having actors interview for real jobs, or video-recording real interviews) or a qualitative approach. In a field setting it is impossible to control fluctuations in speech rate, intonation, hesitation, volume, and voice quality-all of which are known to influence listener evaluations - not to mention other non-verbal confounds. In order to isolate the effect of accent, the accent stimuli should ideally be nearly identical in all other respects, and so an experimental paradigm is the only reasonable option. Qualitative interviews capture finer details of individual experience and cultural norms (cf. Baratta 2015), and are used in this project to gather contextual information, but they are not reliable for large-scale comparison of judgments.

The project is comprised of four related experiments, described below: Experiment 1 involved a large-scale survey of prevailing perceptions of job suitability for the five British accents across a broad cross section of the UK. Experiment 2 focused on a specific employment sector, law, and looked at the extent to which such accent effects interfere with lawyers' objective judgments of entry-level candidates' knowledge. Experiment 3 ran a variant of Experiment 1 but using a slider to track real-time ratings. Finally, Experiment 4 designed and tested a number of interventions for improving recruiters' ability to discern expert content and to disregard accent. All three experiments additionally investigated the role of demographic, psychological, and social factors in accounting for specific biases.

The experiments all used a similar methodological design, namely a verbal guise design, a variant of the matched-guise technique for studying language attitudes (Lambert, Hodgson, Gardener and Fillenbaum 1960). We recorded mock interview responses that represented law trainee candidates giving answers to ten different sample law interview 
questions. These varied only in accent, with two native speakers for each of the five accents listed in Table 1 to control for individual speaker effects. The content of the mock responses was developed in close consultation with lawyers and covers a range of typical interview topics, both technical and general, helping to distract listeners from the focus on accent and minimise response bias, whereby listeners might alter their responses in line with what they believe to be the researcher's desired responses. An example of a mock answer is provided in (2).

(2) (Think about the 2008 recession. What effects do you think that had on us as a firm?)

There would have been less business overall for the firm, so that must have had various effects. Employees are expensive, so you might have thought about reorganising both lawyers and support staff. You would have also thought about fixed costs, like the lease on the firm's main office. There would have been more competition for legal work from other firms, so you would have had to think about how many lawyers were assigned to deals, and how the deals were priced.

The experiments used a between-subjects design with pseudo-randomised audio stimuli, such that each participant heard two versions of each accent and no mock answer or speaker more than once. The stimuli were delivered in a formal register using standard grammar, regardless of accent, so as to approximate educated interview speech. Recordings were restricted to men's voices to avoid potential confounding effects of gender stereotypes (cf., e.g., Trudgill 1972).

Listeners were asked to judge each audio sample they heard according the following five questions on a 10-point Likert scale (see Rudman and Glick 1999; Rakić, Steffens and Mummendey 2011): How would you rate the overall quality of the candidate's answer? Does the candidate's answer show expert knowledge? In your opinion, how likely is it that the candidate will succeed as a lawyer? Is the candidate somebody that you personally would like to work with? How would you rate the candidate overall? The two main design differences in Experiment 2, as described in section 3.2, were (a) responses included a 'good' quality version and a 'bad' quality version, independently normed as such by a separate panel of lawyers, and (b) as the participants were professional lawyers and recruiters, the final question was replaced by "How likely would you be to recommend hiring this candidate?".

The population sample for Experiment 1 was a demographically representative sample of 1106 listeners from around the UK, created with the help of a market research company. To enhance ecological validity in Experiment 2, we collected data in law firms, mimicking hiring situations in the scenarios presented, involving senior staff in participating firms, and framing the exercise as part of our goal of building interview training materials for students and recruiters. Experiments 3 and 4 were conducted using Prolific, a company used widely in research for recruiting paid participants online.

Next we turn to the four core methodological questions set out earlier, highlighting specific innovations and design choices that helped target these goals more accurately.

\subsection{Methods for measuring the impact of accent bias on hiring decisions (Experiment} 2)

In this section, we focus in more detail on how the adapted design used for Experiment 2 starts to address the first of our key methodological questions in (1), namely how we can know whether accent bias is actively affecting the ability to perceive skills crucial for employment and success in an elite profession. 
Attitudes to accent might distort how competent certain candidates appear, and such differences could lead to a disproportionate failure to identify talent and potential in members of certain social groups, impeding social mobility and leading to underrepresentation of some social groups in elite professions. But we cannot assume that accent bias has these effects. A person may like a particular accent - indeed perceptual bias is a human universal (Tajfel 1969) - but may nevertheless be capable of disregarding those personal preferences when trying to identify the most competent person for the job. Research designs therefore need to not only identify the presence or absence of accent preferences, but also establish whether these distort other judgements, particularly those that lead to material outcomes such as employment.

In other words, a finding of a simple preference for accent $\mathrm{A}$ over accent $\mathrm{B}$ is informative, but it cannot tell us the extent to which those preferences interfere with the objective judging of competence. All three scenarios shown in Figure 1 are consistent with a preferential rating of Accent A, but have very different real-world consequences.

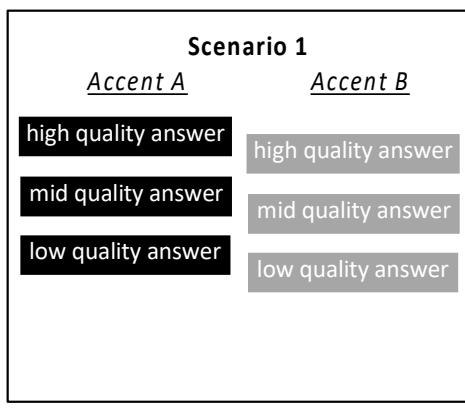

i. No effect

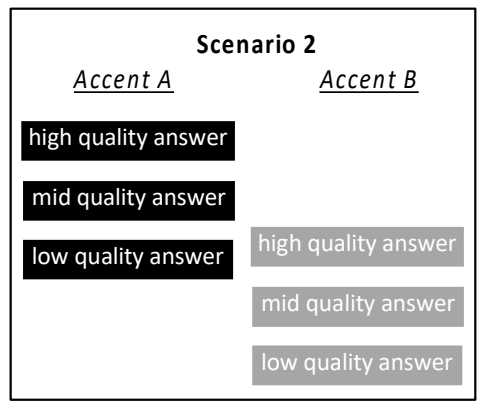

ii. Global effect

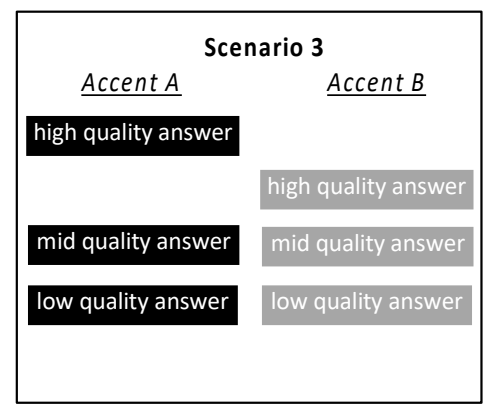

iii. Conditioned effect

Figure 1: Examples of potential effects of accent preference on employment outcomes

Experiment 2 makes use of a design that can distinguish among these. Focusing on law as a sample professional sector, Experiment 2 looks at whether accent bias interferes with professional recruiters' ability to evaluate the content of a candidate trainee's response. Law is one of several sectors identified as particularly lacking in diversity and being prone to subjective measures of aptitude (Ashley et al. 2015; The Guardian 14/7/15; SRA 2014; Sullivan 2010). Our work with law firms included both the North and South of England, in order to capture the potential for very different regional norms. Participants in Experiment 2 were all lawyers or recruiters employed in large corporate law firms. For recruiting, it was necessary to work closely with the School of Law in the researchers' universities, as well as with an Advisory Board that included such representatives as Aspiring Solicitors (www.aspiringsolicitors.co.uk). Participants were also recruited via researchers' and advisors' professional networks. The majority of data were collected on site in law firms.

In the design of Experiment 2, we added a further manipulation of the stimuli used in Experiment 1, drawing on studies cited earlier that incorporated conditionality. Rather than having just one scripted answer to each of 10 questions, the stimuli in Experiment 2 include better and worse versions. The 20 mock answers (i.e. 2x10), an example of which was provided earlier in (2), were developed with senior professionals in the legal sector. Their quality difference was confirmed through a survey in which 40 lawyers rated the texts in their written form. These ratings indicate a consistent and statistically significant difference between ratings of the 'good' and the 'poor' answer for each question. 
This baseline allows us to examine whether accent differences distort a recruiter's ability to distinguish a good answer from a poorer one. It allows us to move beyond reporting simple accent preferences and establish whether or not these interfere with the primary task of the recruiter: recognising the quality of an interview response. A prestigious accent (RP) may make a poor answer sound more knowledgeable, and a low prestige accent may cause a good answer to be rated on a par with poor answers that were delivered in RP. We can also establish the strength of such perceptual distortions: are 're-rankings' significant enough that the RP-speaking Candidate A gets heard as more competent than the EE-speaking Candidate $\mathrm{B}$, even though Candidate A gave a response that was objectively worse? Or does the distortion only slightly reduce the attractiveness of Candidate B relative to A, but still maintain their relative rank based on the quality of their answers? Do we in fact find that, even though a person dislikes an accent, they are nevertheless able to identify the most competent person for a job based on the content of their responses? Finally, the design allows us to see whether accent-driven distortions to perception are greater when responses are poor, when responses are good, or regardless of response type.

In these ways we are able to specify much more precisely the nature and extent of double standards that new recruits may face in professional contexts, and the specific 'burden of proof' experienced by members of disadvantaged groups.

\subsection{Methods for identifying sources of bias (Experiments 1 and 2)}

The methods so far describe patterns of bias. In order to begin to explain the prevalence of certain subjective preferences - (the second key methodological challenge listed in (1) - the survey materials must also capture details of hypothesised predictors. Experiments 1 and 2 are therefore also designed to explore regional differences and other social or psychological origins of any observed bias.

As noted earlier, the fields of psychology and economics provide us with precise models of types of bias and the sources these may derive from. Although it can be challenging to distinguish reliably among different theoretical predictions, a detailed set of respondent data is an important first step. We therefore ask participants to provide information about themselves in a number of different domains, each set designed to probe different possible sources of bias. Participants were always asked for this information at the end of a survey, to minimise the behavioural impact of a participant becoming self-conscious of a particular identity trait. The categories included were:

i) Demographic - e.g. gender, ethnicity, region of origin, highest level of education, occupation

ii) Social diversity and experience - e.g. social mobility, e.g. parents' education, geographical mobility, e.g. via postcodes over lifetime, regional and ethnic diversity of their own social networks (Sharma 2017)

iii) Linguistic - e.g. own accent, exposure to different UK accents (Stuart-Smith, Pryce, Timmins and Gunter 2013), familiarity with the recorded accent

iv) Psychological — e.g. diversity tolerance (adapted from Fuertes et al. 2000); motivation to control prejudice (adapted from Dunton and Fazio 1997); beliefs about presence of class-based or region-based prejudice (adapted from Swim et al. 1995)

The statistical analysis used mixed-effect models to examine the effect of these factors, if any, on participants' ratings. Results are not presented in detail here, but a few preliminary findings can be noted. Age emerged as one of the strongest factors driving accent ratings in the nationwide survey (Levon, Sharma, Ye, Cardoso and Watt 2019a), such that older listeners gave lower ratings overall and also downgraded the two working class London 
accents (EE and MLE), with a significant difference between RP and MLE. RP received the highest rating across ages except for the youngest respondents, who showed a significant reversal in the relative rank of MLE. Motivation to control prejudice, a psychological factor not included in sociolinguistics studies to date, was also one of the strongest factors in willingness to report accent bias. And finer interactions between a listener's class, region, and presence of expert content in the response are also found. Overall, these preliminary findings indicate significant patterns of bias against certain accents in England, particularly MLE, though these are moderated by factors of age, class, region, perceived discrimination, and motivation to control prejudice.

The inclusion of detailed respondent information permits the project to address more fine-grained questions in further analysis: Does a person's social embedding (networks, employment, mobility) or psychological makeup (beliefs, preferences) more clearly influence their subjective responses to accents? Does a listener's bias against a non-standard accent relate more to their degree of familiarity with it, or to its low prestige in wider society? For example, if ratings of MLE, a variety known to be associated with lower social status, are consistently low regardless of whether a listener has had personal exposure to it or not, we can infer that social norms rather than personal experience are strong in driving accent preferences.

\subsection{Identifying 'shibboleths' (Experiment 3)}

Our third methodological challenge in (1) was to find ways to understand the exact linguistic target of accent evaluations. This goal stands to benefit from recent technological advances in the study of sociophonetics. In particular, we can now better identify the precise trigger for subjective responses. Is a stereotypical persona evoked by the gradual accretion of tiny acoustic signals? Or only when those signals cluster together and cross a particular threshold for salience? Or perhaps even by a single 'shibboleth' that evokes a strong stereotype, e.g. the pronunciation of thing as fing?

As noted earlier, research has only recently developed sophisticated enough tools to investigate the precise target of accent attitudes, particularly in real-time, and there is also very little examination of how attitudes vary with interspeaker variation within a given accent, e.g. whether negative attitudes are always attenuated when a user of a given accent has a less 'strong' accent.

In this project we tested a new set of methods for more closely tracking real-time responses to accent shibboleths and also methods for examining degrees of accentedness. We utilised adjustable on-screen sliders for ratings so that participants could modify their qualitative evaluations of candidates in real-time while listening to audio samples. At the start of the presentation of each stimulus, participants were told that they could adjust their ratings of "How well the candidate is doing" by moving a graphical sliding scale on the computer screen throughout the recording (cf. Watson and Clark 2013). They completed a practice exercise to familiarise themselves with the interface beforehand. Once the stimulus recording was complete, participants rated the candidate's overall performance by responding to the same series of 10-point Likert-type questions used in Experiment 1.

The collection of both a real-time response measure and more global responses allows us to examine what respondents are specifically responding to in the audio signal: specific accent shibboleths (indicated by correlations between real-time ratings and linguistic features present in the speech signal), clustered accent features, overall accent, an interaction of accent with content, or perhaps not accent at all. Change-point analyses (Killick and Eckley 2014) can be used to quantitatively examine real-time ratings of response quality, and to determine the extent to which significant changes in participant reactions are correlated with particular linguistic features or clusters of features in the different accents (Watson and Clark 2015). 
Preliminary results reported in Cardoso, Levon, Sharma, Watt and Ye (2019) indicate that certain accents, e.g. MLE, are highly sensitive to degree of accentedness while others, e.g. Northern accents, appear to be less so. However, preliminary analysis using Generalized Additive Modelling (Wood 2006) of second-by-second ratings indicates that, at least for these stimuli, listeners are not responding to individual shibboleths as much as relying on very early global classification of speakers as soon as they hear the accent. This is notably consistent across demographic groups of listeners, and shows an interaction with content, such that expert content can mitigate these effects (Levon, Sharma, Ye, Cardoso, Watt 2019b).

\subsection{Assessing the efficacy of interventions (Experiment 4)}

A final challenge in the study of language and discrimination is the question of how firms or institutions should respond if such biases are found in a given sector. Can any form of intervention effectively address the problem of language-based discrimination? Experiment 4 examines a number of interventions to test their ability to improve respondents' ability to disregard accent and discern expert content.

As noted, numerous intervention designs have been explored and evaluated in the fields of Psychology and Management Studies. Some aim to displace stereotypical associations themselves, while others accept their presence but aim to attenuate their impact on behaviour. Experiment 4 was designed to test a number of explicit and implicit types of intervention alongside a control condition that lacks an intervention, in order to understand the relative effectiveness of such exercises for controlling accent bias. We included interventions designed to increase awareness of bias, a statement of intention to implement a given behaviour, commitment to fairness and objectivity, increased accountability, and multiculturalism. Some of these resemble commonly used formats in generic corporate diversity training, e.g. generic reminders to avoid bias, while others adopt less widely used wording based on previous research.

The interventions appear to have differential effects on recruiters' awareness and responses to non-standard accents. Detailed analysis will be forthcoming; here we simply emphasise the goal of this final component of the project, namely to convert this set of observations regarding the efficacy of specific interventions into practical, usable language awareness and anti-bias training materials for a range of stakeholders. These include students planning a career in a traditionally elite profession, university careers representatives, recruiters in law firms and other corporate professions, HR professionals more generally, policy makers, and the general public. We also incorporate in these materials insights gained from informal consultations with lawyers and HR professionals, to enrich our collective awareness of language-related issues. For example, lawyers sometimes note the difficulty of anticipating client preferences, ones they may not themselves share. They have also reported to us a rapidly changing climate in law firms, with much more proactive anti-bias awareness and engagement already in place. On the negative side, they have also noted the greater informality of appointment procedures as individuals become more senior in law firms, with increased potential for implicit bias and greater challenges in observing and tracking bias at that level. Finally, some professionals experience casual forms of discrimination in the workplace that may not be detectable in designs that focus exclusively on formal recruiting.

These complexities of accent bias in professional contexts call for creative and multidimensional research designs. We have argued that these methodological challenges are best addressed through a creative integration of best practices from linguistics, social psychology, economics, and management, and by triangulating multiple types of data to better understand the problems of language-based discrimination and to design workable solutions. 


\section{Acknowledgement}

This work was supported by the Economic and Social Research Council, UK ("Accent Bias and Fair Access in Britain," ES/P007767/1).

\section{References}

Alemoru, K. (2015) "You don't sound like them": A sociolinguistic investigation into how race interacts with the perception and attitude towards Multicultural London English. Unpublished MA dissertation, University of Sheffield.

Altendorf, U. (2003) Estuary English: Levelling at the interface of RP and South-Eastern British English. Tübingen: Gunter Narr.

Arrow, K. (1973) The theory of discrimination. In Ashenfelter, O. and A. Rees (eds.) Discrimination in Labor Markets 3-33. Princeton: Princeton University Press.

Ashley, L., J. Duberley, H. Sommerlad, and D. Scholarios (2015) A qualitative evaluation of non-educational barriers to the elite professions. London: Social Mobility and Child Poverty Commission. https://dera.ioe.ac.uk/23163/1/A_qualitative_evaluation_of_noneducational_barriers_to_the_elite_professions.pdf

Ashton, H. and S. Shepherd (2012) Work on Your Accent: Clearer Pronunciation for Better Communication. London: Harper Collins.

Atkins, C. P. (1993) Do employment recruiters discriminate on the basis of nonstandard dialect? Journal of Employment Counselling 30: 108-118.

Axt, J.R., M.C Casola and B. A Nosek (2018) Reducing social judgment biases may require identifying the potential source of bias. Personality and Social Psychology Bulletin (preprint)

Baratta, A. (2015) Standard English but not the standard accent. Paper presented at the Resisting the Standard conference, June, University of Sheffield.

Baugh, J. (2003) Linguistic profiling. In Makoni, S., G. Smitherman, A. Ball and A. Spears (eds.) Black linguistics 155-168. London: Routledge.

Beal, J. (2004) The Phonology of English Dialects in the North of England. In Kortmann, B. and E. W. Schneider (eds.) A handbook of varieties of English, vol. 1 113-133. Berlin: Mouton de Gruyter.

Beal, J. (2009) Enregisterment, commodification and historical context: "Geordie” versus "Sheffieldish". American Speech 84: 138-156.

Becker, G. (1957) The economics of discrimination. Chicago: University of Chicago Press.

Bertrand, M. and S. Mullainathan (2004) Are Emily and Greg more employable than Lakisha and Jamal? A field experiment on labor market discrimination. The American Economic Review 94: 991-1013.

Bishop, H., N. Coupland and P. Garrett (2005) Conceptual accent evaluation: Thirty years of accent prejudice in the UK. Acta Linguistica Hafniensia 37: 131-154.

Blanden, J., A. Goodman, P. Gregg and S. Machin (2005) Changes in intergenerational income mobility in Britain. In Corak, M. (ed.) Generational income mobility in North America and Europe 122-146. Cambridge, MA: Cambridge University Press

Buscha, F. and P. Sturgis (2017) Declining social mobility? Evidence from five linked censuses in England and Wales 1971-2011. British Journal of Psychology 69(1): 154182.

Campbell-Kibler, K. (2008) I'll be the judge of that: Diversity in social perceptions of (ING). Language in Society 37(5): 637-659.

Cardoso, A., E. Levon, D. Sharma, D. Watt and Y. Ye (2019) Inter-speaker Variation and the Evaluation of British English Accents in Employment Contexts. Proceedings of the International Congress of Phonetic Sciences 2019. Available at: www.accentbias.org 
Carlson, H. and M. McHenry (2006) Effect of accent and dialect on employability. Journal of Employment Counseling 43: 70-83.

Chartered Institute for Personnel Development (CIPD). (2006) Diversity in Business: How much progress have employers made? https://www.cipd.co.uk/NR/rdonlyres/53CF3D4F2215-4DA6-AEBF-C67C99A67F1C/0/diversbus0606.pdf

Cheshire, J., S. Fox, P. Kerswill and E. Torgersen (2008) Ethnicity, friendship network, and social practices as the motor of dialect change: Linguistic innovation in London. Sociolinguistica 22: 1-23.

Cheshire, J. P. Kerswill, S. Fox and E. Torgersen (2011) Contact, the feature pool, and the speech community: The emergence of Multicultural London English. Journal of Sociolinguistics 15: 151-196.

Clark, L. and E. Schleef (2010) The acquisition of sociolinguistic evaluations among Polishborn adolescents learning English: evidence from perception. Language Awareness 19: 299-322.

Connelly, B., S. T. Certo, R. D. Ireland and C. R. Reutzel (2011) Signaling Theory: A review and assessment. Journal of Management 37: 39-67.

Coupland, N. and H. Bishop (2007) Ideologised values for British accents. Journal of Sociolinguistics 11: 74-93.

Darity, W. and P. Mason (1998) Evidence on discrimination in employment: Codes of color, codes of gender. The Journal of Economic Perspectives 12: 63-90.

Devine, P. G., P. S. Forscher, A. J. Austin and W. T. L. Cox (2012) Long-term reduction in implicit racial prejudice: A prejudice habit-breaking intervention. Journal of Experimental Social Psychology 48: 1267-1278.

Dixon, J., B. Mahoney and R. Cocks (2002) Accents of guilt? Effects of regional accent, race, and crime type on attributions of guilt. Journal of Language and Social Psychology 21: 162-168.

Dunton, B. C. and R. H. Fazio (1997) An individual difference measure of motivation to control prejudiced reactions. Personality and Social Psychology Bulletin 23: 316-326.

Fabricius, A. (2002) Ongoing change in RP: Evidence for the disappearing stigma of tglottalling. English World-Wide 23: 115-136.

Fabricius, A. (2005) Mobility, contact and an accent norm: The case of Received Pronunciation. In Preisler, B., A. Fabricius, H. Haberland, S. Kjærbeck, and K. Risager (eds.) The consequences of mobility. Roskilde: Roskilde University Department of Language and Culture.

Fox, K. (2004) Watching the English: The Hidden Rules of English Behaviour. London: Arnold.

Fry, S. (2011) 'Fry's English Delight' Series 4: Class. Series on Radio 4, 1 August 2011.

Fuertes, J. N., M. L. Miville, J. J. Mohr, W. E. Sedlacek and D. Gretchen (2000) Factor structure and short form of the Miville-Guzman Universality-Diversity Scale. Measurement and Evaluation in Counseling and Development 33: 157-169.

Garrett, P., N. Coupland and A. Williams (1999) Evaluating Dialect in Discourse: Teachers' and Teenagers' Responses to Young English Speakers in Wales. Language in Society 28: 321-354.

Giles, H. (1970) Evaluative reactions to accents. Educational Review 22: 211-227.

Giles, H. (1971) Ethnocentrism and the evaluation of accented speech. British Journal of Social and Clinical Psychology 10: 187-188.

Giles, H., S. Baker and G. Fielding (1975) Communication length as a behavioural index of accent prejudice. International Journal of the Sociology of Language 6: 73-81. 
Giles, H., P. Wilson and A. Conway (1981) Accent and lexical diversity as determinants of impression formation and perceived employment suitability. Language Sciences 3: 91103.

Heath, A. and S. Cheung (2006) Ethnic penalties in the labour market: Employers and discrimination. DWP Research Report no. 341.

https://webarchive.nationalarchives.gov.uk/20130125104217/http://statistics.dwp.gov.u k/asd/asd5/rports2005-2006/rrep341.pdf

Hiraga, Y. (2005) British attitudes towards six varieties of English in the USA and Britain. World Englishes 24: 289-308.

Huang, B. (2013) The effects of accent familiarity and language teaching experience on raters' judgments of non-native speech. System 41: 770-785.

James, L. and O. Smith (2012) Get Rid of Your Accent for Business: The English Speech Training Manual, Part 3. London: Business and Technical Communication Services.

Jones, O. (2011) Chavs: The Demonization of the Working Class. London: Verso.

Kalin, R., D. Rayko and N. Love (1980) The perception and evaluation of job candidates with four different ethnic accents. In Giles, H., W. P. Robinson and P. M. Smith (eds.) Language: Social Psychological Perspectives 197-202. Oxford: Pergamon Press.

Kerswill, P. (2001) Mobility, meritocracy and dialect levelling: the fading (and phasing) out of Received Pronunciation. In P. Rajamäe and K. Vogelberg (eds.) British Studies in the New Millennium: The Challenge of the Grassroots 45-58. Tartu: University of Tartu.

Killick, R. and I. A. Eckley (2014) changepoint: An R package for changepoint analysis. Journal of Statistical Software 58: 1-19.

Kushins, E. (2014) Sounding like your race in the employment process: An experiment on speaker voice, race identification, and stereotyping. Race and Social Problems 6: 237248.

Labov, W., S. Ash, M. Ravindranath, T. Weldon, M. Baranowski and N. Nagy (2011) Properties of the sociolinguistic monitor. Journal of Sociolinguistics 15(4): 431-463.

Lambert, W., R. C. Hodgson, R. C. Gardener and S. Fillenbaum (1960) Evaluational reactions to spoken languages. Journal of Abnormal and Social Psychology 60: 44-51.

Lerner, J.S. and P.E. Tetlock (1999) Accounting for the Effects of Accountability. Psychological Bulletin 125: 255-275.

Levon, E. and S. Fox (2014) Social Salience and the Sociolinguistic Monitor: A Case Study of ING and TH-fronting in Britain. Journal of English Linguistics 42(3): 185-217.

Levon, E. and I. Buchstaller (2015) Perception, cognition and linguistic structure: The effect of linguistic modularity and cognitive style on sociolinguistic processing. Language Variation and Change 27: 319-348.

Levon E., D. Sharma, Y. Ye, A. Cardoso and D. Watt (2019a) Accent bias and perceptions of professional competence in the U.K. Presentation at the International Conference on Language Variation in Europe (ICLaVE 10), Leeuwarden, The Netherlands. Available at: www.accentbias.org

Levon E., D. Sharma, Y. Ye, A. Cardoso and D. Watt (2019b) Real-Time Evaluations of British Accents: The effect of social and psychological factors on judgments of professional competence. Presentation at New Ways of Analyzing Variation (NWAV 48), Oregon, United States. Available at: www.accentbias.org

Lippi-Green, R. (1997) English with an accent: Language, Ideology and Discrimination in the United States. London: Routledge

Llamas, C. and D. Watt (2015) Scottish, English, British? Innovations in attitude measurement. Language and Linguistics Compass 8: 610-617. 
Llamas, C., D. Watt and D. Johnson (2009) Linguistic accommodation and the salience of national identity markers in a border town. Journal of Language and Social Psychology 28: 381-407.

Milroy, J. and L. Milroy (1985) Authority in Language: Investigating Language Prescription and Standardisation. London: Routledge.

Montgomery, C. (2007) Northern English Dialects: A Perceptual Approach. PhD thesis, University of Sheffield. Online resource: <http://etheses.whiterose.ac.uk/1203/>, accessed 11/10/2018.

Montgomery, C. and E. F. Moore (2018) Evaluating S(c)illy Voices: The effects of salience, stereotypes, and co-present language variables on real-time reactions to regional speech. Language 94(3): 629-661.

Mugglestone, L. (1995) Talking proper: The rise of accent as social symbol. Oxford: Clarendon Press.

Phelps, E. (1972) The statistical theory of racism and sexism. The American Economics Review 62: 659-661.

Purkiss, S. L. S., P. L. Perrewé, T. L. Gillespie, B. T. Mayes and G. R. Ferris (2006) Implicit sources of bias in employment interview judgments and decisions. Organizational Behavior and Human Decision Processes 101(2): 152-167.

Purnell, T., W. Idsardi and J. Baugh (1999) Perceptual and phonetic experiments on American English dialect identification. Journal of Language and Social Psychology 18 (1): $10-30$.

Puttenham, G. (1589) The Arte of English Poesie. Facsimile edition. Ed. Baxter Hathaway. Kent, Ohio: Kent State University Press, 1970.

Rakić, T., M. C. Steffens and A. Mummendey (2011) When it matters how you pronounce it: The influence of regional accents on job interview outcome. British Journal of Psychology 102: 868-883.

Reay, D. (2009) Making Sense of White Working Class Educational Underachievement. In K.P. Sveinsson (ed.) Who Cares about the White Working Class? 22-28. Chichester: St Richards Press.

Renn, J. and J. M. Terry (2009) Operationalizing style: Quantifying style shift in the speech of African American adolescents. American Speech 84: 367-390.

Rich, J. (2014) What do field experiments of discrimination in markets tell us? A metaanalysis of studies conducted since 2000. IZA Discussion Papers 8584. Bonn: Institute for the Study of Labour.

Rickford, J. and A. E. Rickford (1995) Dialect Readers Revisited. Linguistics and Education 7: 107-128.

Roberts, C., E. Davies and T. Jupp (1992) Language and Discrimination: A study of communication in multi-ethnic workplaces. London: Longman.

Rudman, L. A. and P. Glick (1999) Feminized management and backlash toward agentic women: The hidden costs to women of a kinder, gentler image of middle-managers. Journal of Personality and Social Psychology 77: 1004-1010.

Sharma, D. (2017) Scalar effects of social networks on language variation. Language Variation and Change 29(30): 393-418.

Sharma, D. and B. Rampton (2015) Lectal focusing in interaction: A new methodology for the study of style variation. Journal of English Linguistics 43(1): 3-35.

Sharpe, E. and J. H. Rowles (2011) How to Do Standard English Accents: From Traditional $R P$ to the New 21st-Century Neutral Accent. London: Oberon.

Shaw, G. B. (1916) Pygmalion. New York: Brentano.

Smith, E. (2010) Underachievement, failing youth and moral panics. Evaluation and Research in Education 23: 37-49. 
Snell, J. (2010) From sociolinguistic variation to socially strategic stylisation. Journal of Sociolinguistics 14: 618-644.

Solicitors Regulation Authority (SRA) (2014) Diversity in the Legal Profession: Workforce data for solicitors' firms 2013/14. http://www.sra.org.uk/solicitors/diversitytoolkit/diverse-law-firms.page

Stuart-Smith, J., G. Pryce, C. Timmins and B. Gunter (2013) Television can also be a factor in language change: Evidence from an urban dialect. Language 89: 501-536.

Sullivan, R. (2010) Barriers to the Legal Profession. Legal Services Board (LSB).

Swift, J. (1712) A Proposal for Correcting, Improving and Ascertaining the English Tongue. London: Benj. Tooke

Swim, J. K., K. J. Aikin, W. S. Hall and B. A. Hunter (1995) Sexism and racism: Oldfashioned and modern prejudices. Journal of Personality and Social Psychology 68: 199-214.

Tajfel, H. (1969) Cognitive aspects of prejudice. Journal of Social Issues 25: 79-97.

Tombs, A. and S. Rao Hill (2014) The effect of service employees' accent on customer reactions. European Journal of Marketing 48: 2051-2070.

Toynbee, P. (2011) 'The Class Ceiling' BBC Radio 4 series (first episode 8 September 2011)

Trudgill, P. (1972) Sex, covert prestige and linguistic change in urban British English of Norwich. Language in Society 1: 179-195.

Trudgill, P. (1974) The Social Differentiation of English in Norwich. Cambridge: Cambridge University Press.

Trudgill, P. (1975) Accent, Dialect and the School. London: Edward Arnold.

Trudgill, P. (1986) Dialects in Contact. Oxford: Blackwell

Uhlmann E.L. and G.L. Cohen. 2005. Constructed criteria: Redefining merit to justify discrimination. Psychological Science 16: 474-480.

van Hofwegen, J. and W. Wolfram (2010) Coming of age in African American English: A longitudinal study. Journal of Sociolinguistics 14(4): 427-455.

Wang, Z., A. Arndt, S. Singh and M. Biernat (2009) The Impact of Accent Stereotypes on Service Outcomes and Its Boundary Conditions. Advances in Consumer Research 36: 940-941.

Watson, K. and L. Clark (2013) How salient is the NURSE SQUARE merger? English Language and Linguistics 17: 297-323.

Watson, K. and L. Clark (2015) Exploring listeners' real-time reactions to regional accents. Language Awareness 24: 38-59.

Watt, D. (2002) "I don't speak with a Geordie accent, I speak, like, the Northern accent": Contact-induced levelling in the Tyneside vowel system. Journal of Sociolinguistics 6: 44-63.

Wood, M., J. Hales, S. Purdon, T. Sejersen and O. Hayllar (2009) A test for racial discrimination in recruitment practice in British cities. DWP Research Report no. 607. http://www.bollettinoadapt.it/old/files/document/3626ATESTFORRACIALDI.pdf

Wood, S. (2006) Generalized additive models: An introduction with R. Boca Raton: CRC Press.

Zentella, A.C. (1997) Growing up bilingual: Puerto Rican children in New York. Oxford: Blackwell.

Zschirnt, E. and D. Ruedin (2016) Ethnic discrimination in hiring decisions: A meta-analysis of correspondence tests 1990-2015. Journal of Ethnic and Migration Studies 42: 11151134. 